\title{
The IL-33-ILC2 pathway protects from amebic colitis
}

Md Jashim Uddin ${ }^{1,2}$, Jhansi L. Leslie ${ }^{1}$, Stacey L. Burgess ${ }^{1}$, Noah Oakland ${ }^{1}$, Brandon Thompson ${ }^{3}$, Mayuresh Abhyankar $^{1}$, Julio Revilla ${ }^{1}$, Alyse Frisbee ${ }^{3}$, Alexandra N. Donlan ${ }^{3}$, Pankaj Kumar ${ }^{4}$ and William A. Petri Jr $\mathbb{D}^{1,2,3 凶}$

(c) The Author(s) 2021

Entamoeba histolytica is a pathogenic protozoan parasite that causes intestinal colitis, diarrhea, and in some cases, liver abscess. Through transcriptomics analysis, we observed that $E$. histolytica infection was associated with increased expression of IL-33 mRNA in both the human and murine colon. IL-33, the IL-1 family cytokine, is released after cell injury to alert the immune system of tissue damage. Treatment with recombinant IL-33 protected mice from amebic infection and intestinal tissue damage; moreover, blocking IL-33 signaling made mice more susceptible to amebiasis. IL-33 limited the recruitment of inflammatory immune cells and decreased the pro-inflammatory cytokine IL- 6 in the cecum. Type 2 immune responses were upregulated by IL-33 treatment during amebic infection. Interestingly, administration of IL-33 protected RAG2 ${ }^{-1-}$ mice but not RAG2 ${ }^{-1-} \mathrm{Yc}^{-1-}$ mice, demonstrating that IL33-mediated protection required the presence of innate lymphoid cells (ILCS). IL-33 induced recruitment of ILC2 but not ILC1 and ILC3 in RAG2 ${ }^{-1-}$ mice. At baseline and after amebic infection, there was a significantly higher IL13+ILC2s in C57BL/J mice, which are naturally resistant to amebiasis, than CBA/J mice. Adoptive transfer of ILC2s to RAG $2^{-1-} \mathrm{YC}^{-1-}$ mice restored IL-33-mediated protection. These data reveal that the IL-33-ILC2 pathway is an important host defense mechanism against amebic colitis.

Mucosal Immunology (2022) 15:165-175; https://doi.org/10.1038/s41385-021-00442-2

\section{INTRODUCTION}

Diarrhea-related illnesses are one of the major causes of death worldwide in children under 5 years of age, resulting in approximately 500,000 mortalities annually ${ }^{1}$. Entamoeba histolytica is a pathogenic protozoan that is the primary causative agent of amebic dysentery. Diarrhea-associated amebic infections are correlated with growth faltering in pre-school aged children ${ }^{2}$. In addition to diarrhea, infections by $E$. histolytica can also cause intestinal colitis and liver abscess, and this parasite accounts for 55,000 deaths worldwide annually ${ }^{3}$. Currently, the primary treatment for amebiasis is metronidazole, a drug which, in addition to toxic side effects, has been insufficient to fully eliminate parasites from the gut ${ }^{4}$. In an effort to find an effective therapeutic intervention, we sought to characterize the host immune response to amebic infection.

Host factors, along with parasite genetics and environmental factors, are likely responsible for heterogeneous outcomes of $E$. histolytica infection ${ }^{5}$. Once inside the colon, amebic trophozoites can attach to intestinal epithelial cells to cause cell death and tissue damage ${ }^{6}$. Intestinal tissue damage by $E$. histolytica is associated with the production of pro-inflammatory cytokines, including IL-1 $\beta, \quad \mathrm{IL}-6, \mathrm{IL}-8, \mathrm{IFN}-\gamma$, and $\mathrm{TNFa}^{7}$. These proinflammatory cytokines may in part affect susceptibility by regulating the recruitment of neutrophils and macrophages, cells that have been shown to be critical in protection from amebiasis in a mouse model ${ }^{8}$. For example, IFN- $\gamma^{-}$or TNFa-treated macrophages have been shown to have potent amebicidal activity in vitro ${ }^{9}$. In children, increased production of IFN- $\gamma$ by peripheral blood mononuclear cells was associated with decreased susceptibility to amebiasis ${ }^{10}$. In contrast, excessive pro-inflammatory responses could be deleterious and cause host tissue damage. For example, increased TNFa in children was associated with amebic diarrhea, and blocking TNFa with neutralizing antibody was protective in a mouse model of amebiasis $^{11,12}$. A type 2 cytokine, IL-25, mainly released from intestinal tuft cells, was shown to protect from amebic colitis and downregulated pro-inflammatory cytokines including TNFa, IL$17 \mathrm{a}$, and IL-23 $3^{12,13}$. IL-25 treatment increased the expression of type 2 cytokines IL- 4 and IL-5 and promoted the recruitment of eosinophils ${ }^{12}$. Thus, complex interdependent collaborations between intestinal epithelial cells and immune cells dictate the outcome of $E$. histolytica infection. Understanding these interactions is critical to finding an effective intervention for amebiasis.

To identify host immune pathways modulated in human colonic tissue upon amebic infection, we performed an unbiased transcriptomics analysis. We observed that an IL-1 family cytokine IL-33 was upregulated in human and mouse colon. This was of interest because a number of recent studies have revealed the role of IL-33-mediated protection from experimental and infection-induced colitis in mouse models ${ }^{14-16}$. Similar to IL-25, IL-33 activates type 2 innate lymphoid cells (ILC2s) and induces the expression of type 2 cytokines, and may even be a more potent inducer of type 2 immune responses ${ }^{13,14,17}$. However, the role of IL-33 and ILC2s in amebic colitis has not previously been studied. Using a mouse model of amebiasis, we demonstrate here that IL-33 protected from amebic infection and colonic tissue damage. IL-33 treatment dampened overall inflammation, with decreased IL-6, CD45+ immune cells, and Ly6C ${ }^{\text {hi }}$ inflammatory

\footnotetext{
${ }^{1}$ Department of Medicine: Infectious Diseases and International Health, University of Virginia School of Medicine, Charlottesville, VA, USA. ${ }^{2}$ Department of Pathology, University of Virginia School of Medicine, Charlottesville, VA, USA. ${ }^{3}$ Department of Microbiology, Immunology and Cancer Biology, University of Virginia School of Medicine, Charlottesville, VA,

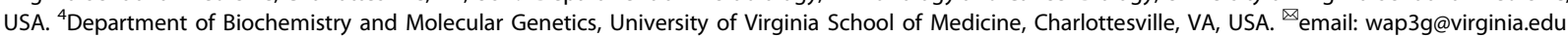


Day 1 vs Day 60

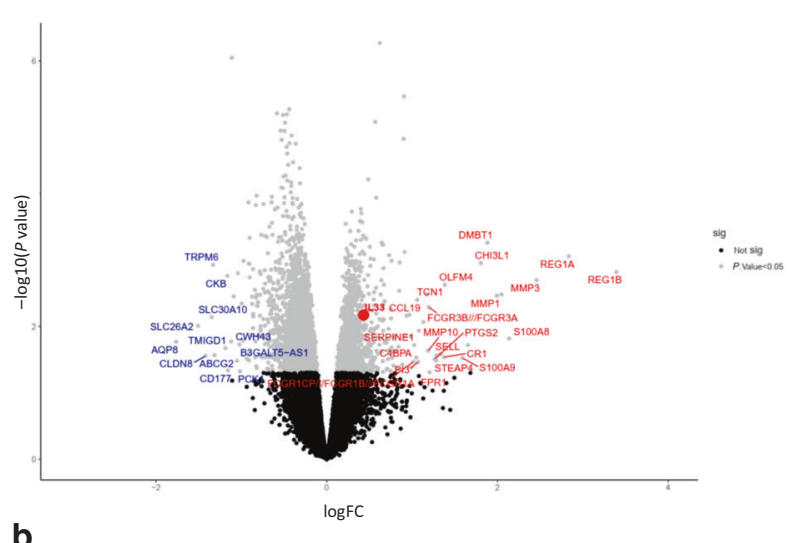

b

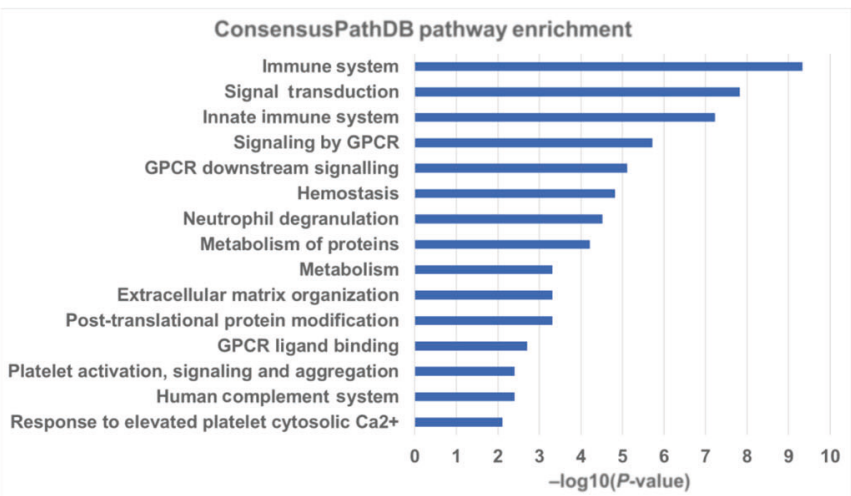

C

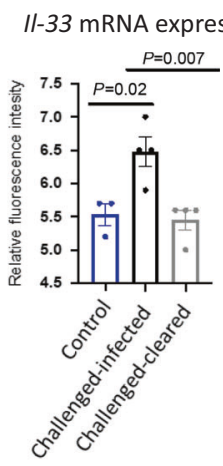

d

IL-33 protein

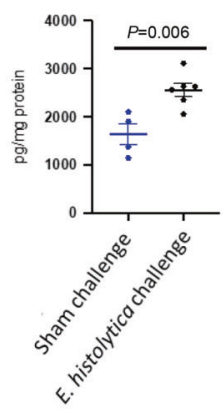

Fig. 1 Amebic infection induces IL-33 expression in the colon of humans and mice and upregulates host immune-related pathways in colonic tissue. a, b Transcriptomic analyses were performed on colon biopsies collected at acute amebic infection (at day 1) and convalescence (at day 60) of eight patients. a Volcano plot shows IL-33 (red dot) among upregulated genes. b Pathway enrichment analysis of upregulated transcripts ( $\log F C \geq 0.4$ ) using Consensus PathDB tool. $\mathbf{c}, \mathbf{d}$ IL-33 mRNA and protein were measured in mouse cecal tissue. c II-33 mRNA expression by microarray from C57BL/6J mice, $n=3-4$ per group (data from Mackey-Lawrence et al.) ${ }^{53}$. d IL-33 protein by ELISA in cecal tissue lysate from CBA/J mice, data representative of two independent experiments, $n=4-5$ per group. Statistical significance was determined by one-way ANOVA and unpaired $t$ test. Error bars indicate SEM.

monocytes in lamina propria. We observed that IL-33 did not require the presence of $\mathrm{T}$ and $\mathrm{B}$ cells to confer protection from amebic colitis, however did require ILC2s.

\section{RESULTS}

Amebic infection induces IL-33 expression in humans and in the mouse model

To understand the host immune response to amebic infection, we investigated differential gene expression in human colonic biopsies via Affymetrix microarray ${ }^{18}$. Samples were collected from eight individuals at the time of infection and during convalescence (60 days after recovery). One of the significantly upregulated genes was II33 (Fig. 1a), encoding for the cytokine IL-33, which is known as a nuclear alarmin and an inducer of type 2 immune responses. IL-25, an IL-17 family cytokine and also an inducer of type 2 immune response, was previously shown to be protective to amebic colitis ${ }^{12}$. Hence, we sought to test whether IL-33 had any role in disease protection via type 2 immunity. We first tested if IL-33 was similarly increased in the intestinal tissue upon $E$. histolytica infection in the mouse model of amebiasis. IL33 mRNA and protein were measured in C57BL/6J and CBA/J mouse strains. Wildtype (WT) $\mathrm{C} 57 \mathrm{BL} / 6 \mathrm{~J}$ mice are resistant to amebic colitis and start clearing the infection as early as $12 \mathrm{~h}$ post challenge ${ }^{19}$. At $12 \mathrm{~h}$ post challenge, mice that remained infected had significantly higher expression of $1 / 33$ mRNA compared to sham-challenged mice and mice that cleared the infection (Fig. 1c).
Unlike C57BL/6J mice, CBA/J mice are susceptible to amebic colitis and remain infected for several weeks and acquire colitis pathologically. On day 3 post challenge, IL-33 protein was significantly higher in cecal tissue of CBA/J mice but not C57BL/ 6J mice compared to sham-challenged mice (Fig. 1d and Supplementary Fig. 1a). We also measured IL-25 protein in cecal tissue of $\mathrm{C} 57 \mathrm{BL} / 6 \mathrm{~J}$ mice and CBA/J mice. As previously reported ${ }^{12}$, amebic infection decreased IL-25 in cecal tissue (Supplementary Fig. 1b). There was no significant difference of IL-33 and IL-25 in the small intestine (Supplementary Fig. 1a, b). The total number of goblet cells and tuft cells was also not altered with amebic infection (Supplementary Fig. 1d). Together, this indicated that our mouse model of infection similarly resulted in IL-33 induction as in humans.

The upregulated genes ( $\log F C>0.4)$ from the human colon transcriptome were analyzed with the Consensus PathDB pathway enrichment tool. Innate/adaptive immunity and G-protein coupled receptor signaling were among the upregulated pathways (Fig. 1b). Interestingly, pathways involved in tissue repair (hemostasis, extracellular matrix organization) were also significantly upregulated. These results suggested that increased IL-33 might be involved in the induction of barrier repair mechanisms to protect gut tissue from amebic colitis.

\section{IL-33 protects from amebic colitis}

As infection increased IL-33 in both humans and in mice, we utilized the mouse model of amebic colitis to investigate if IL-33 
$a$ Infection rate by culture

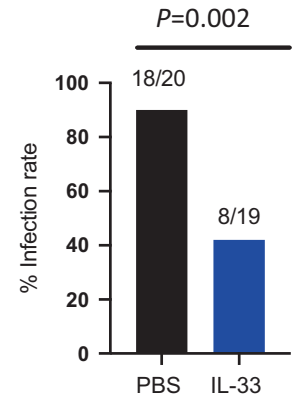

d

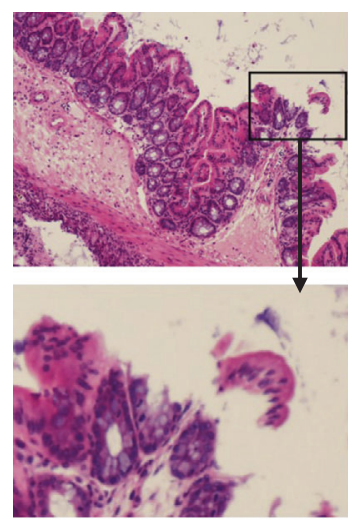

b

E. histolytica burden by qPCR

C

Weight loss

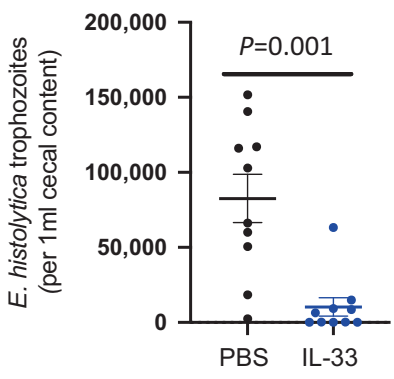

IL-33

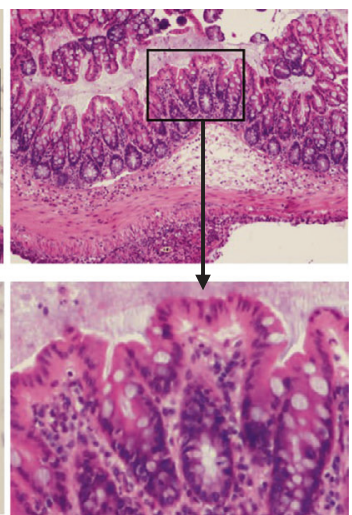

f

E. histolytica burden by qPCR

g

Weight loss
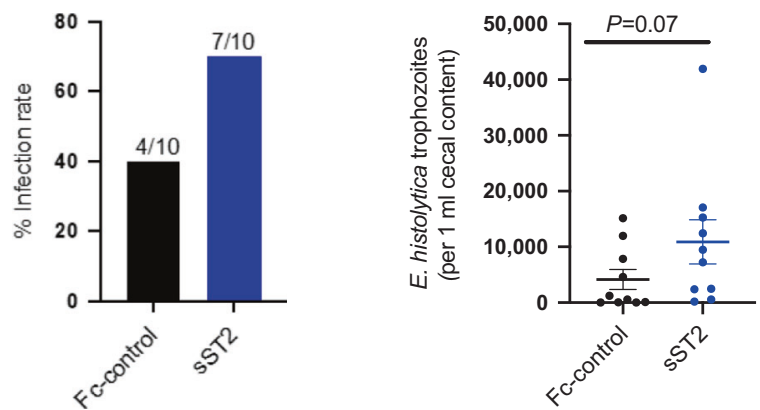

h

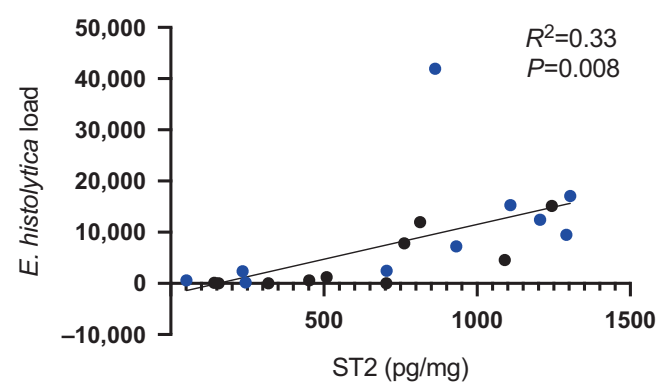

protected from amebiasis. CBA/J mice were treated with $0.75 \mu \mathrm{g}$ of recombinant IL-33 intraperitoneally for 8 days (from day-3 to day +4 of the amebic challenge). On day +5 of the challenge, mice were sacrificed to collect cecal content and cecal tissue to determine the infection rate and epithelial damage. Treatment

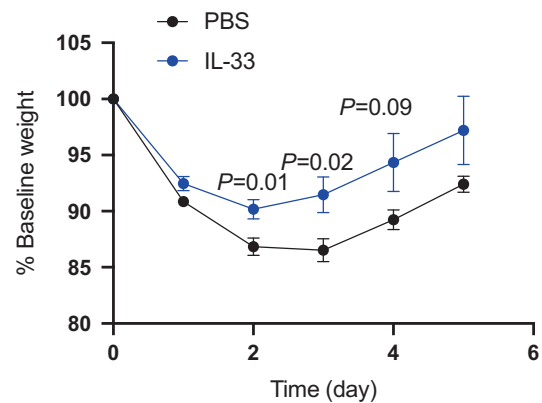

Epithelium damage

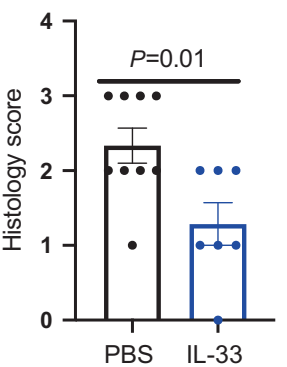

with IL-33 significantly protected mice from infection and weight loss (Fig. 2a-c). We investigated epithelial tissue damage by hematoxylin and eosin (H\&E) staining during amebic infection. Where amebic infections induced tissue damage both in the cecum and colon, the small-intestinal tissue was intact 
Fig. 2 IL-33 protects from amebic infection and epithelial tissue damage in mice. a-d CBA/J mice were injected intraperitoneally with 0.75 $\mu \mathrm{g}$ of IL-33 or PBS each day for 8 days. On day 4 mice were challenged with E. histolytica trophozoites. Cecal content and cecal tissue were harvested on day 9 (day 5 post E. histolytica challenge). a Infection rate measured by amebic culture from cecal content. b E. histolytica DNA, measured by qPCR. $\mathbf{c}$ Weight loss. d Epithelial damage scored by H\&E staining of cecal tissue. e-h Impact of soluble ST2: C57BL/6J mice were intraperitoneally injected $5 \mathrm{ug} /$ mouse soluble ST2 (IL-33 receptor). e infection rate by amebic culture from cecal content. f $E$. histolytica DNA by qPCR. g Weight loss. h Correlation of amebic DNA load and ST2 concentration in cecal tissue (blue dots represent mice in soluble ST2 group and black dots represent control group). a Data pooled from two independent experiments $(n=9-10)$. b-d Data representative of two independent experiments $(n=9-10)$. e-h Data pooled from two independent experiments $(n=5-10)$. Statistical significance was determined by Fisher's exact test and unpaired $t$ test. Error bars indicate SEM.

(Supplementary Fig. 2a). H\&E staining showed that the IL-33treated group had a more intact epithelium compared to the PBStreated group (Fig. 2d and Supplementary Fig. 2b). As our lab previously showed that Reg $1^{-1-}$ epithelial cells were more susceptible to amebic induced apoptosis ${ }^{18}$, we investigated if IL33 treatment might alter intestinal Reg1b. We found increased Reg1b protein in the cecal content of IL-33-treated mice compared to PBS-treated mice (Supplementary Fig. 2c). These data supported a role of IL-33 to clear ameba and protect and/or repair the colonic epithelial layer from damage.

We endeavored to know whether endogenous IL-33 signaling had a role in this protection. IL-33 signals through binding the IL-1 receptor-like protein $\mathrm{ST} 2^{20}$. The IL-33 receptor ST2 can be found in both a cell surface-bound form and a soluble form. The soluble form of ST2 can bind with IL-33 and act as a negative regulator of the IL-33 signaling pathway ${ }^{21}$. Downregulation of IL-33 signaling by adding soluble ST2 made mice more susceptible to infection (Fig. 2e, f). Soluble ST2-treated mice lost significantly more weight than vehicle-treated mice upon challenge with amebic trophozoites (Fig. 2g). Notably, the concentration of ST2 in colonic tissue was positively correlated with the colonic burden of E. histolytica (Fig. 2h). Together, these data demonstrated that endogenous IL33 protected from colonic amebiasis.

\section{IL-33 regulates the type 2 immune response and dampens colonic inflammation upon amebic infection}

IL-33 has been shown to induce a type 2 immune response in intestinal tissue during helminth and bacterial infections ${ }^{15,22}$. We hypothesized that IL-33 may be protecting in our model by promoting a type 2 immune response. To examine this, we used RT qPCR to examine if the transcription of cytokines that are associated with a type 2 response, $I-4, \|-5$, and $I I-13$, were altered. While IL-33 treatment increased the transcription of IL-5 and IL-13, we did not observe any significant change of IL-4 transcript levels (Fig. 3a). Others have found that IL-33 can induce IL-13 secretion from ILCs leading to differentiation of goblet cells ${ }^{23}$. Intestinal goblet cells secret a mucus-gel that is known to contribute to the clearance of amebic trophozoites ${ }^{24,25}$. Thus, we sought to determine if IL-33 was altering goblet cells in our model. Examining periodic acid-Schiff (PAS)-stained fixed tissues, we found that goblet cells were increased in the IL-33 administered group (Fig. 3b). The primary structural component of the mucusgel is the MUC2 mucin. In concordance with our histological analysis, we also found that IL-33-treated mice had higher expression of Muc2 mRNA compared to PBS-treated mice (Fig. 3c).

IL-5 is crucial in the maturation and release of eosinophils ${ }^{26}$. Coordinately, flow-cytometric analysis of cecal tissue revealed that administration of IL-33 resulted in eosinophilia during amebic infections (Fig. 3g, top panel and Supplementary Fig. 4). Since IL33 treatment upregulated colonic eosinophils, we asked if IL-33mediated protection was dependent on eosinophilia. To test that, we depleted eosinophils in IL-33-treated mice with anti-SiglecF monoclonal antibody (Supplementary Fig. 3a). Treatment with anti-SiglecF successfully depleted eosinophils but not alternatively activated macrophages or monocytes in colonic tissue (Supplementary Fig. $3 \mathrm{e}-\mathrm{g}$ ). There was not an increase in infection rate with anti-SiglecF administration, and amebic load and weight loss were not different between the treatment and control groups (Supplementary Fig. 3b-d). These data suggested that IL-33mediated protection from amebic colitis was not conferred by eosinophils.

In addition to regulating the type 2 response, IL-33 has been shown to dampen the inflammatory response during intestinal infection ${ }^{15}$. In our model, there were a significantly decreased number of CD45+ cells in cecal tissue in IL-33-treated mice (Fig. 3d). In addition to total CD45+ cells, the IL-33-treated group had a significantly decreased number of Ly6 $\mathrm{C}^{\text {hi }}$ inflammatory monocytes (Fig. 3g, lower panel and Supplementary Fig. 4) as well as the pro-inflammatory cytokine IL-6 (Fig. 3e). There was a trend of lowered Ly6G + neutrophils, although that was not statistically significant $(P=0.067)$ (Fig. $3 g$, lower panel and Supplementary Fig. 4). Interestingly, IL-33 treatment expanded the number of alternatively activated macrophages, which are thought to be anti-inflammatory (Fig. 3g, middle panel and Supplementary Fig. 4). Markers of anti-inflammatory macrophages such as Chil3 and Arg1 were also found to be significantly higher in IL-33treated mice (Fig. 3f). Since IL-33 upregulated Chil3 expression, which has previously been shown to be involved in tissue repair during acute nematode infection ${ }^{27}$, we sought to investigate the role of Chil3 in amebiasis. We measured Chil3 in C57BL/6J and CBA/J mice by ELISA. Interestingly, C57BL/6J mice had higher Chil3 expression in cecal tissue at baseline compared to CBA/J mice (Supplementary Fig. 5a). Amebic infection upregulated Chil3 in both strains of mice (Supplementary Fig. 5a). Treatment with recombinant Chil3 cleared amebic load from the cecum but did not protect from weight loss (Supplementary Fig. 5b-d). Together these data demonstrated that IL-33 induced a type 2 immune response and diminished inflammations during amebic colitis.

\section{IL-33-mediated protection from amebic colitis requires ILCs but not $T$ and $B$ cells}

IL-33 has been shown to promote the function of regulatory T cells as well as ILC2s in intestinal tissue to protect from barrier disruption ${ }^{16,28}$. Moreover, IL-33 has been shown to act on B cells to promote the production of $\lg \mathrm{A}$, which, in turn, protects mice from colitis and colitis-associated cancer ${ }^{29}$. Hence, it was important to determine which cell types are responsible for IL-33-mediated protection from amebiasis. We treated RAG2 ${ }^{-1-}$ mice (deficient of $T$ and $B$ cells) with recombinant IL-33 and observed that even in the absence of T and B cells, IL-33 still protected from amebic infection and weight loss (Fig. $4 a-c)$. These data indicated that the presence of $T$ and $B$ cells was not necessary for this IL-33-mediated defense.

As anticipated, RAG2 ${ }^{-1-}$ mice that received IL-33 had significantly more Gata3 + ILC2s in their colon compared to vehicletreated mice (Fig. 4d, e and Supplementary Fig. 6c), while the number of ILC1s and ILC3s was not significantly different (Fig. 4f, g). Most of the Gata3+ ILC2 also expressed the IL-33 receptor (ST2) (Fig. 4e and Supplementary Fig. 6c), suggesting that ILC2s acted downstream of IL-33 signaling. These data suggested a potential role of ILC2s in IL-33 promoted defense from amebic colitis. We were interested in measuring ILC2s in WT C57BL/6J and CBA/J mice. Since amebic infection did not induce epithelial damage in 

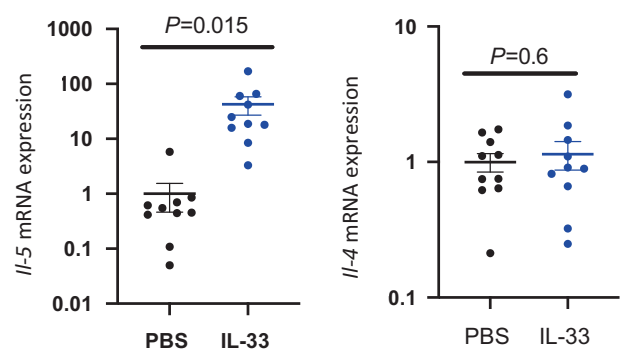

C

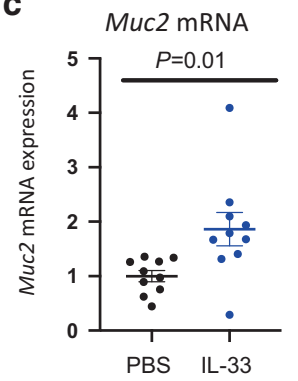

d

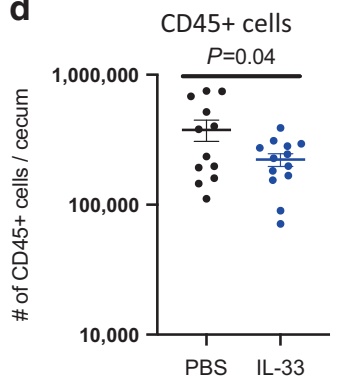

b

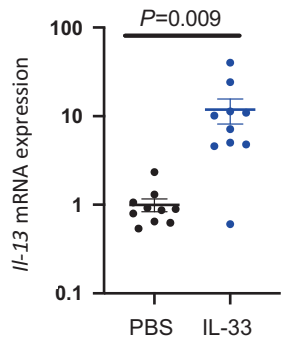

e

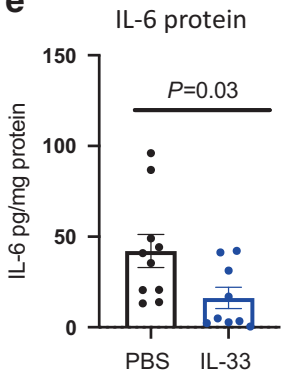

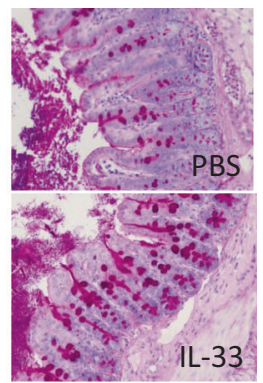

f

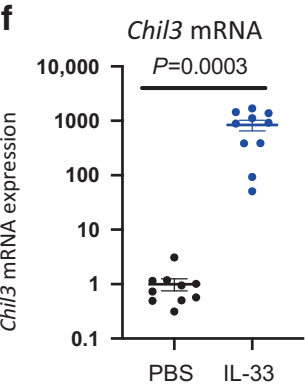

Goblet cells
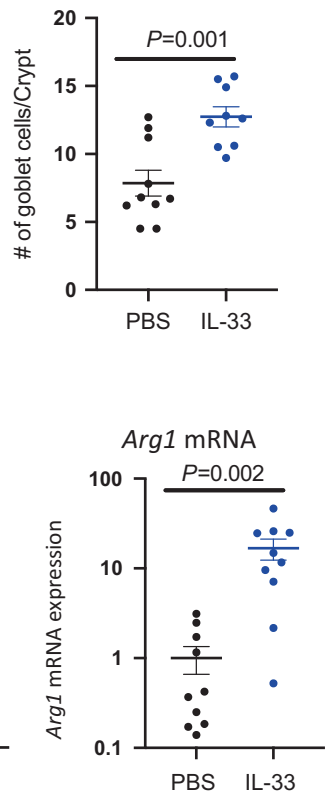

g
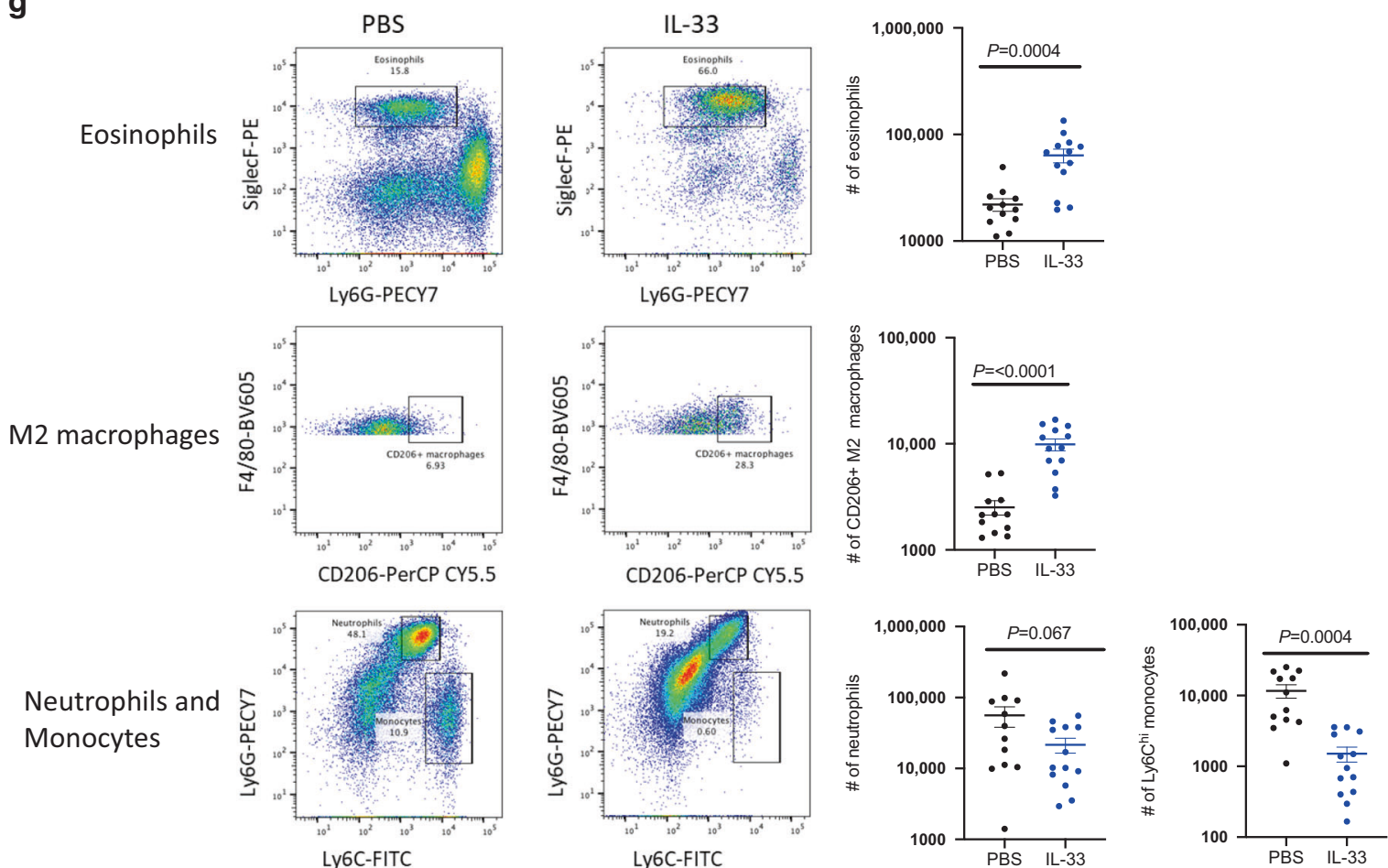

Fig. 3 IL-33 upregulates type 2 immune response and dampens inflammation during amebic colitis. CBA/J mice were injected intraperitoneally with $0.75 \mu \mathrm{g}$ of IL-33 or PBS each day for 8 days. On day 4, mice were challenged with E. histolytica trophozoites. Cecal tissue was collected on day 9 (day 5 of amebic challenge) from IL-33- or PBS-treated mice. a mRNA expression of type 2 cytokines. b PAS-stained goblet cells by microscopy. c Muc2 mRNA expression. $\mathbf{d}$ Total CD45+ cells in cecal tissue by flow cytometry. e IL-6 protein by ELISA from cecal lysate. f Chil3 and Arg1 (M2 macrophages marker) mRNA expression. $\mathbf{g}$ Flow cytometry gating and immune profiling of myeloid cells. a-f Data representative of two independent experiments $(n=5-10)$. g Data pooled from two independent experiments $(n=5-10)$. Statistical significance was determined by unpaired $t$ test. Error bars indicate SEM.

$\mathrm{SI}$, we focused the ILC2 characterization only in cecal and colonic tissue. Interestingly, C57BL/6J mice had a significantly higher IL13+ILC2s at baseline and during amebic infection than CBA/J mice (Supplementary Fig. 6a, b). Further studies will inform if this higher number of ILC2s contributes to providing resistance against amebic colitis in C57BL/6J mice.

To further delineate the importance of ILCs, we utilized a $\mathrm{RAG}^{-1-} \mathrm{Yc}^{-1-}$ strain of mouse that does not have ILCs in addition 


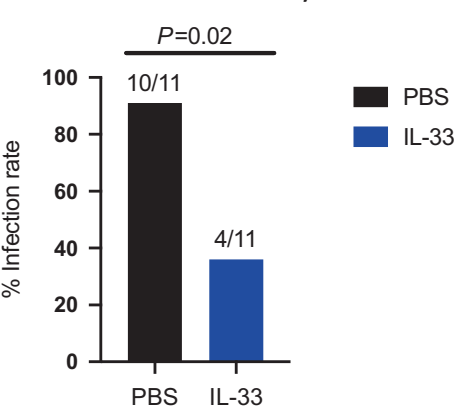

b

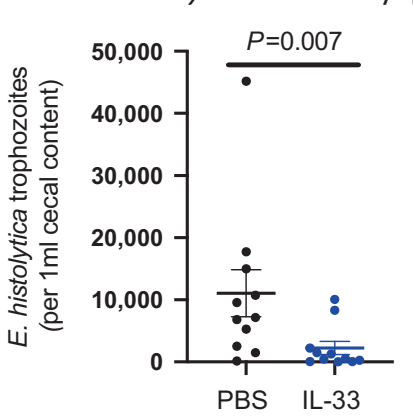

C Weight loss

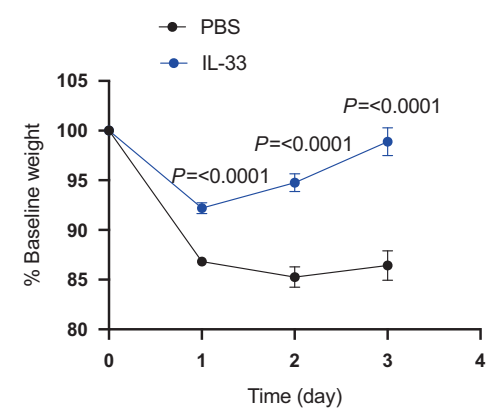

d

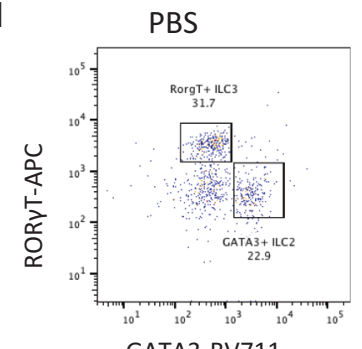

e

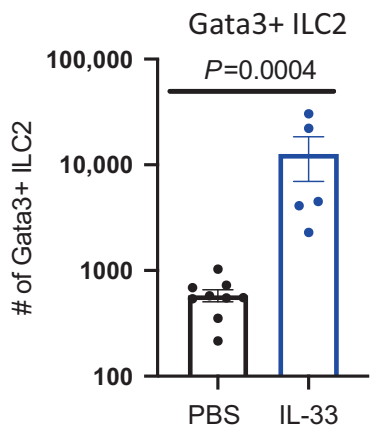

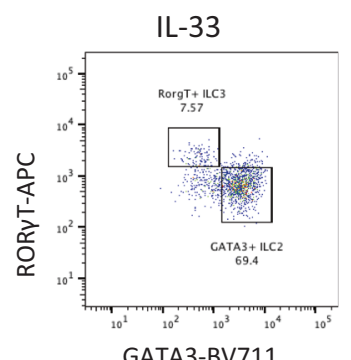

GATA3-BV711

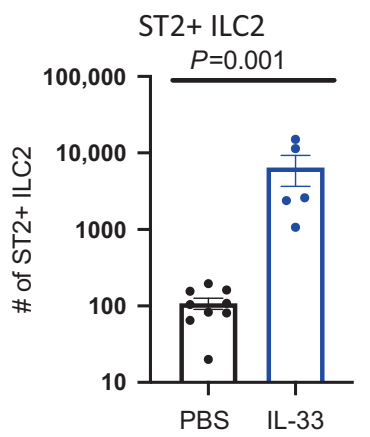

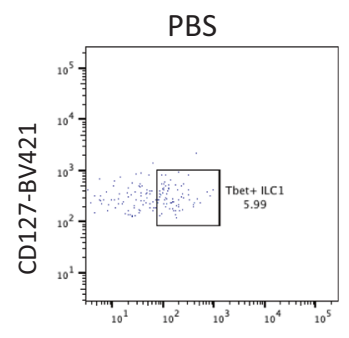

Tbet-PE DAZZLE 594

f
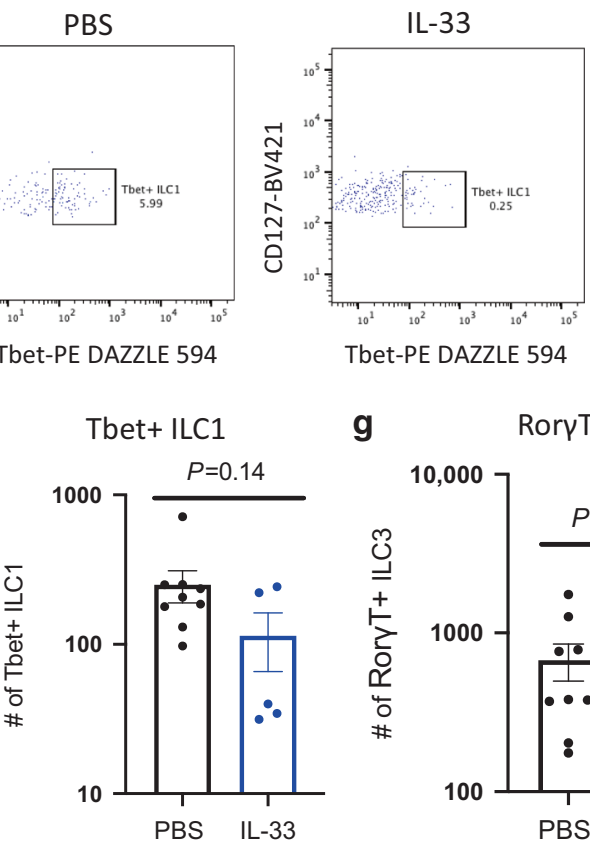

g

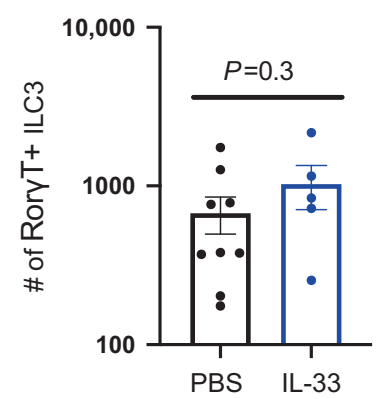

Fig. 4 IL-33 protects RAG2 ${ }^{-/-}$mice and upregulates Gata3 + and ST2 + ILC2s. a-g RAG2 ${ }^{-1-}$ mice (C57BL/6 background) were treated with IL33 and PBS followed by an amebic challenge. On day 3 post amebic challenge, mice were sacrificed to collect cecal content and cecal tissue. a Infection rate determined by amebic culture of cecal content. $\mathbf{b}$ E. histolytica DNA measured by qPCR from cecal content. $\mathbf{c}$ Weight loss. $\mathbf{d}$ Flow cytometry gating to determine the total number of ILC1, ILC2, and ILC3. e Total number of Gata3+ and ST2+ ILC2s in cecal tissue. f Number of ILC1. g Number of ILC3. a-c Data pooled from two independent experiments $(n=5-6)$. d-g Data representative of two independent experiments $(n=5-9)$. Statistical significance was determined by Fisher's exact test and unpaired $t$ test. Error bars indicate SEM.

to lacking $\mathrm{T}$ and $\mathrm{B}$ cells. While IL-33 was able to protect RAG2 ${ }^{-1-}$ mice, protection was lost in $\mathrm{RAG}^{-1-} \mathrm{\gamma c}^{-1-}$ mice (Fig. 5a-c). In addition, upregulation of type 2 immune responses was abrogated in $\mathrm{RAG}^{-/-} \mathrm{Yc}^{-1-}$ mice (Fig. $5 \mathrm{~d}$, e). This included MUC2 mucin that was upregulated in $\mathrm{RAG}^{-1-}$ mice but not in $\mathrm{RAG}^{-/-} \mathrm{\gamma c}^{-/-}$mice upon IL-33 treatment (Fig. 5f).

\section{Adoptive transfer of ILC2s restored IL-33-mediated protection in $\mathrm{RAG2}^{-I-} \mathrm{Yc}^{-l-}$ mice}

To determine if ILC2s acted downstream of IL-33 signaling during protection from amebic colitis, we adoptively transferred ILC2s into $\mathrm{RAG2}^{-1-} \mathrm{Yc}^{-/-}$mice. ILC2s were isolated from mouse spleen, mesenteric lymph node, and colonic tissue and enriched using magnetic cell separation. Isolated cells were then expanded in vitro and activated in the presence of IL-33 ${ }^{13,15}$. ST2+ILC2s were flowsorted and adoptively transferred into $\mathrm{RAG}^{-1-} \mathrm{\gamma c}^{-1-}$ mice $\left(5 \times 10^{5}\right.$ cells/mouse) through intraperitoneal injection. Both mice receiving ILC2s and control mice were treated with IL-33 (Fig. 6a). While 100\% of the control RAG2 ${ }^{-1-} \mathrm{Yc}^{-/-}$mice remained positive for ameba on day 3 post amebic challenge, $55 \%$ of $\mathrm{RAG}^{-1-} \mathrm{Yc}^{-1-}$ mice that received ILC2s were culture-negative (Fig. 6b). E. histolytica DNA load was also significantly lower in ILC2s administered mice (Fig. 6c). ILC2 treatment also protected $\mathrm{RAG}^{-1-} \mathrm{\gamma c}^{-1-}$ mice from weight loss (Fig. 6d). The successful transfer of ILC2s in RAG2 $2^{-1-} \mathrm{Yc}^{-1-}$ mice was confirmed by flow cytometry analysis (Fig. 6e). These data demonstrate that ILC2s acted downstream of IL-33 during protection from amebic colitis in the mouse model.

\section{DISCUSSION}

The most important discovery of this work is that the nuclear alarmin IL-33 protects from intestinal colitis caused by the protozoan parasite $E$. histolytica. IL-33 was found to mediate innate immunity via an ILC2-driven type 2 immune response. The upregulation of IL-33 transcripts in the human colon during amebic infection was the first indication of a potential role of IL-33 signaling in amebiasis. In the mouse model, treating with recombinant IL-33 cleared trophozoites from the mouse cecum and helped in early recovery from colitis, as evidence by decreased weight loss and epithelial damage. Conversely, inhibition of IL-33 signaling by administration of its soluble receptor ST2 increased susceptibility. Finally, ILC2s were shown to be required 
a Infection rate by culture

b

E. histolytica burden by qPCR
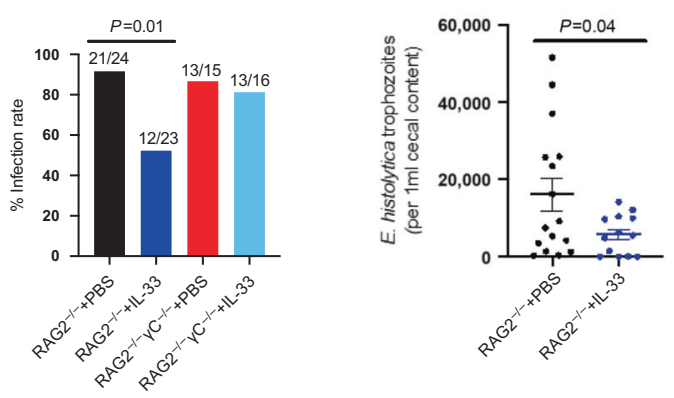

d $I /-5$, and $I /-13$ mRNA by qPCR
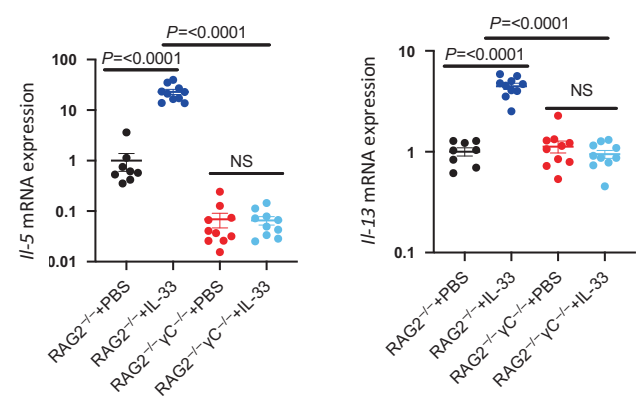

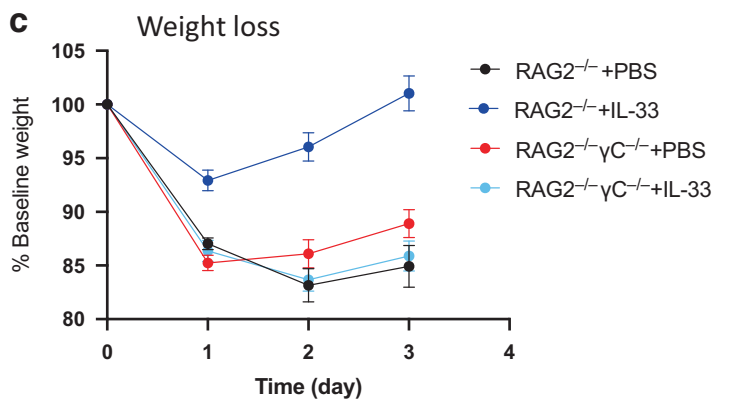

e Chil3, and Arg1 mRNA by qPCR
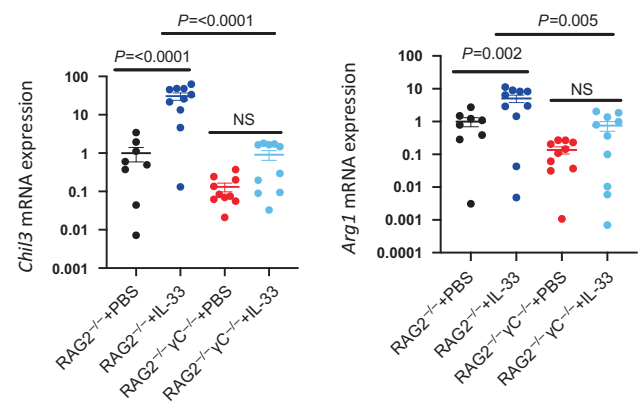

f

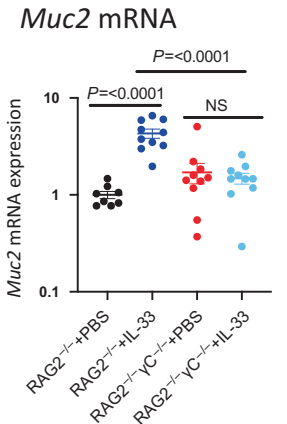

Fig. 5 IL-33-mediated protection from amebiasis and upregulation of type 2 immune responses are lost in RAG2 ${ }^{-/-} \mathrm{Yc}^{-/-} \mathrm{mice}^{\mathrm{RAG}} \mathrm{R}^{-/-}$and $\mathrm{RAG2}^{-1-} \gamma \mathrm{C}^{-1-}$ mice were treated with IL-33 or PBS and challenged with amebic trophozoites. On day 3 of the amebic challenge, mice were harvested to collect cecal tissue and cecal lysate. a Infection rate by amebic culture. b E. histolytica DNA. c Weight loss. d $/ 15$ and $/ 113$ mRNA expression. e Chil3 and Arg1 mRNA. f Muc2 mRNA. a Data pooled from three independent experiments $(n=5-10)$. b Data pooled from two independent experiments $(n=5-10)$. c-f Data representative of two independent experiments $(n=5-10)$. Statistical significance was determined by Fisher's exact test, one-way ANOVA, and unpaired $t$ test. Error bars indicate SEM.

by restoration of IL-33-mediated protection by adoptive transfer into RAG2 $2^{-1-} \mathrm{Yc}^{-1-}$ mice.

IL-33 expression was previously found to be induced in inflamed colonic tissues from ulcerative colitis patients ${ }^{30}$. In mouse models, colonic infections by helminths and bacteria increased IL-33 expression ${ }^{15,31}$. Similarly, we observed induced IL33 expression both in the colon of humans and mice during amebic infection. The mechanisms through which $E$. histolytica infection increases IL-33 expression are not known. Studies show that activation of TLR2/TLR6 signaling with agonist upregulates IL33 transcripts in an NLRP3-dependent manner ${ }^{32}$. Amebic lipopeptidophosphoglycan is recognized by TLR2 and TLR4 on innate and adaptive immune cells resulting in production of effector cytokines ${ }^{33}$. Thus, amebic PAMPs could signal through TLR2/TLR4 to activate NLRP3-inflammasome and induce IL-33 expression. In addition, cell death is a known mechanism of IL-33 induction, and it is possible that IL-33 is upregulated by the novel means by which E. histolytica kills human cells called "trogocytosis" (where amebic trophozoites nibble a part of target cells resulting in cell killing and tissue invasion) ${ }^{6}$. Previous studies showed trophozoites that lacked amoebapore $A$ and the cysteine proteases were unable to induce cellular cytotoxicity ${ }^{7,34}$. Future studies should focus on delineating the contribution of different amebic proteins, including Gal/GalNAc lectin, amoebapore, and cysteine proteases, in the upregulation of IL-33. During cellular death or tissue injury, IL-33 is released from different cells, including endothelial cells, epithelial cells, and peri-cryptal fibroblasts ${ }^{35,36}$. Future studies should also aim to identify cellular sources of IL-33 upon amebic infection.

The upregulation of IL-33 with an amebic infection that is part of the host-protective response may act in part by inducing tissue repair mechanisms that enhance blood coagulation and angiogenesis in colonic tissue ${ }^{16,37}$. Pathway analysis of transcript data derived from colonic biopsies of $E$. histolytica-infected patients revealed that extracellular matrix organization and hemostasis were two of the top ten upregulated pathways. These pathways are involved in the initiation of tissue repair and recovery from epithelial damage. A recent study showed that IL-33 
a

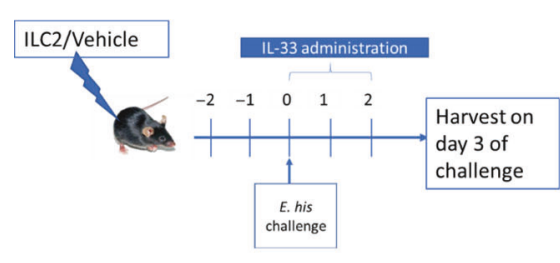

d

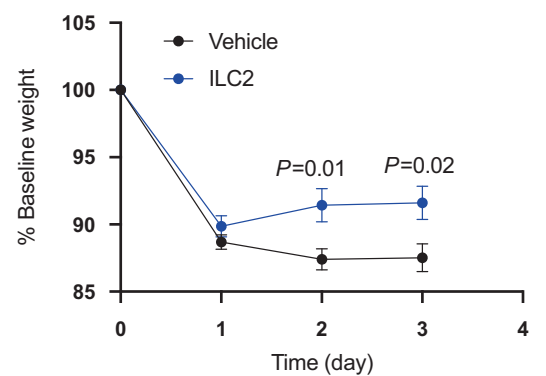

b Infection rate by culture

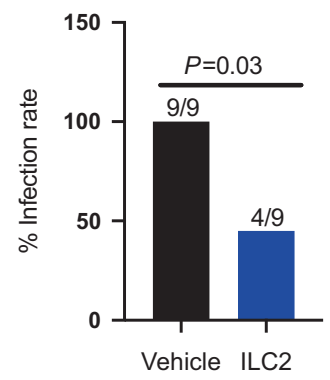

e

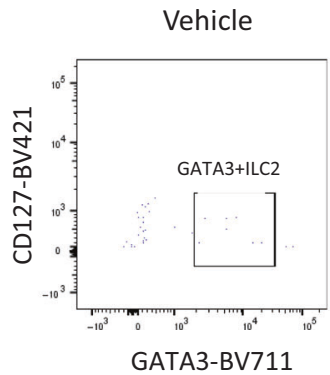

c E. histolytica burden by $\mathrm{qPCR}$

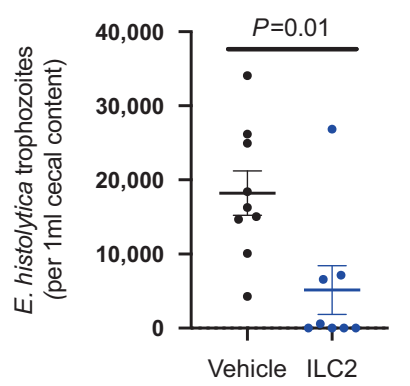

ILC2

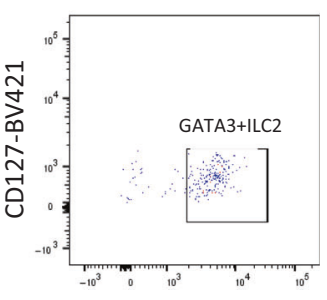

GATA3-BV711

Fig. 6 IL-33 protects ILC2 transplanted RAG2 ${ }^{-1-} \mathbf{~ Y c}^{-/-}$mice from amebic colitis. WT C57BL/6J mice were administered $0.75 \mu$ IL-33 for 4 days. Mouse colons, spleens, and mesenteric lymph nodes were collected, and single-cell suspensions were made. ILCs were enriched using mouse Lineage Cell Depletion Kit. Enriched cells were in vitro expanded toward ILC2s for 4 days by treating with IL-2 (10 ng/ml), IL-7 (10 ng/ml), and IL-33 $(50 \mathrm{ng} / \mathrm{ml})$ followed by flow sorting of ILC2s. RAG ${ }^{-1-} \gamma \mathrm{c}^{-1-}$ mice were transplanted with flow-sorted ILC2s or vehicle followed by amebic challenge. On day 3 post challenge, mice were harvested and cecal tissue and cecal contents were collected. a Experimental outline. b Infection rate by amebic culture of cecal content. c Amebic load by qPCR. d Weight loss. e Representative flow cytometry gating of ILC2s. b-d Data pooled from two independent experiments $(n=3-6)$. Statistical significance was determined by Fisher's exact test and unpaired $t$ test. Error bars indicate SEM.

administration protected mice from colonic tissue damage and increased barrier integrity during $C$. difficile infection ${ }^{15}$. In this study, we found that treatment with IL-33 reduced epithelial damage during amebiasis. IL-33 also reduced parasitic loads from the colon, likely due in part to upregulation of genes involved in innate immune signaling that were overrepresented during acute amebic infection.

IL-33 may act to protect from amebiasis in part by dampening inflammation. Inflammation and immune cell recruitment are host-protective responses toward injury and infection; however, chronic and uncontrolled inflammation could cause collateral damage to the host. With IL-33 treatment, we observed a reduced number of CD45+ cells and Ly6 $\mathrm{C}^{\text {hi }}$ inflammatory monocytes and lower IL-6. IL-6 can induce chronic inflammatory and autoimmune responses ${ }^{38}$. In addition, IL-33 skewed the immune response toward type 2 immunity, which was previously shown to be protective during helminth and bacterial infection ${ }^{15,39}$. Our lab has previously shown that IL-25, an IL-17 family cytokine that can also lead to a type 2 immune response, is protective to intestinal amebiasis $^{12}$. Like IL-33, IL-25 defends from amebic colonization and intestinal tissue damage. IL-25 protected through induction of eosinophilia as observed depletion of eosinophils by neutralizing antibody abrogated protection. With IL-33 treatment, we also observed an increase in colonic eosinophils. Surprisingly, depletion of eosinophils did not abrogate the IL-33-mediated protection (Supplementary Fig. 3). These data suggest that IL-25 and IL-33 use different downstream pathways to protect from amebic colitis. Both basophils and mast cells have the ST2 receptor ${ }^{31}$. Treatment with amebic antigens has been shown to activate mast cells and basophils ${ }^{40,41}$. Future work should focus on determining the role of mast cells and basophils in IL-33-mediated protection from amebic colitis.

IL-33 can activate different ST2+ lymphoid and myeloid cells, including mast cells, basophils, Th2 cells, Treg cells, and ILC2 $\mathrm{s}^{31}$.
We sought to determine if IL-33 was acting on Th2 cells or/and ILC2 cells to protect from amebic colitis by inducing a type 2 immune response. We observed that IL-33 treatment protected $\mathrm{RAG2}^{-1-}$ mice on a $\mathrm{C} 57 \mathrm{BL} / 6$ background in a manner similar to WT CBA/J mice. However, this protection was lost in $\mathrm{RAG2}^{-1-} \mathrm{\gamma C}^{-1-}$ (C57BL/6 background) mice. IL-33-mediated upregulation of IL-5, IL-13, Muc-2, Chil3, and Arg1 transcripts was abrogated in $\mathrm{RAG2}^{-1-} \mathrm{YC}^{-1-}$ mice, but protection was restored by adoptive transfer of ILC2. These data indicated that the presence of ILC2s but not Th2 cells was essential for the upregulation of type 2 immune responses and protection from amebic colitis. Perhaps, ILC2s could be involved in regulating resistance to amebiasis in C57BL/6J mice. Interestingly, we observed that C57BL/6J mice have a significantly higher number of IL13+ILC2s in the gut compared to $\mathrm{CBA} / \mathrm{J}$ mice. In the future, we plan to stimulate the ILC2s isolated from $\mathrm{C} 57 \mathrm{BL} / 6 \mathrm{~J}$ mice and CBA/J mice with different amebic antigens to determine if amebic proteins can directly activate ILC2s.

ILCs are the innate counterpart of CD4+ T helper cells, as evidenced by their effector cytokine production and master transcription factors. Unlike $\mathrm{T}$ cells, they do not have antigen receptors; however, they possess receptors for cytokines and are regulated by IL-33, IL-25, and TSLP upon injury or infection ${ }^{42}$. ILCS have been found to shape intestinal health in diseased or homeostatic conditions. However, the role of ILCs in amebic colitis had not been studied. We observed that IL-33 treatment increased the number of Gata3 + and ST2+ ILC2s in mouse cecal tissue upon amebic infection. Adoptive transfer of ILC2s was sufficient to restore the IL-33-mediated protection from amebic colitis in $\mathrm{RAG}^{-/-} \mathrm{YC}^{-1-}$ mice. IL-33-ILC2-induced goblet cell hyperplasia has been implicated in helminth expulsion from the intestine ${ }^{43}$. In addition, IL-33-activated CD206+ type 2 macrophages were associated with tissue repair in experimental colitis ${ }^{14}$. There was a significantly higher number of goblet cells and expression of 
Muc2 mucin in cecal tissue upon IL-33 treatment. We also observed an increased number of CD206+ alternatively activated macrophages. Future studies should focus on delineating the contribution of IL-13-mediated goblet cells hyperplasia, IL-5, and alternatively activated macrophages in clearance of amebic infection and recovery from colonic tissue damage.

A recent study showed that ILC2s exacerbated amebic liver abscess in a mouse model through IL-5-facilitated accumulation of eosinophils in the abscesses ${ }^{44}$. While type 2 immune-mediated wound healing is key to recovery from colonic tissue damage by infections, this could be deleterious in some organs, including lung and liver ${ }^{14,15,44-47}$. Tissue-specific heterogeneity in ILC2s has been demonstrated, and could contribute to the apparently different roles of ILC2 in response to colitis and liver abscess due to $E$. histolytica ${ }^{48}$. Single-cell RNA sequencing of ILC2s collected from amebic infected colonic tissue could further advance the understanding of downstream effector pathways involved in ILC2mediated protection from amebic colitis and how these differ from liver abscess.

Altogether, we showed for the first time that $E$. histolytica infection upregulates IL-33 transcripts in human and mouse colonic tissue (Supplementary Fig. 7). Endogenous IL-33 signaling and exogenous treatment with recombinant IL-33 protected from amebic colitis. This IL-33-mediated defense from amebiasis was associated with the induction of type 2 immune responses and while IL-33 did not require T and B cells, the presence of ILC2s was sufficient to confer protection (Supplementary Fig. 7). This work showed that the IL-33-ILC2 pathway is important to clear parasitic loads and recover from tissue damage during colitis and could be targeted to design effective interventions.

\section{METHODS}

Mice

Experiments were performed using sex-matched 7- to 10-week-old C57BL/ 6J, CBA/J, Rag2 ${ }^{-1-}$, or Rag2 ${ }^{-1-} \mathrm{YC}^{-1-}$ mice. C57BL/6J and CBA/J mice were purchased from Jackson Labs and housed in specific pathogenfree conditions in the vivarium of the University of Virginia. Rag ${ }^{-1-}$ and $\mathrm{Rag}^{-1-} \mathrm{\gamma C}^{-1-}$ mice with an excluded flora were purchased from Taconic Biosciences. Rag2 ${ }^{-1-}$ and Rag2 $2^{-1} \mathrm{\gamma C}^{-1-}$ mice had bedding swapped twice a week for 3 weeks for the purpose of equilibrating microbiota before experiments were performed. All the experiments were approved by the University of Virginia Institutional Animal Care and Use Committee.

\section{Recombinant IL-33, Chil3, and sST2 treatment}

Mice were administered $0.75 \mu \mathrm{g}$ of recombinant IL-33 (BioLegend, San Diego, CA) or PBS via intraperitoneal injection daily beginning at 3 days before amebic challenge up until 1 day before harvest. For SST2 experiments, mice were treated with $5 \mathrm{ug} /$ mouse of ST2-Fc fusion (R\&D Systems, Catalog \#1004-MR-050) or Fc control for four days (day-1, day 0 , day +1 , and day +2 of amebic challenge) intraperitoneally. For the Chil3 treatment, mice were administered 6 doses (on day-2, $-1,0,+1,+2,+3$ ) of recombinant Chil3 (5ug/dose) (R\&D Systems) via intraperitoneal injection.

\section{E. histolytica infection}

Mice were challenged with $2 \times 10^{6} \mathrm{E}$. histolytica trophozoites (laboratory strain HM1:IMSS) through intra-cecal laparotomy ${ }^{19}$. Trophozoites were resuspended in $150 \mu \mathrm{l}$ of culture media. During surgery, a small incision was made in the abdomen of mice using sterile scissors followed by injection of trophozoites into the cecum directly using a $27 \mathrm{~g}$ needle. The incision was closed using sterile chromic gut sutures ${ }^{19}$. At harvest, cecal contents were collected and cultured in complete TYI-S-33 medium ${ }^{49}$. After $24 \mathrm{~h}$ of culture, the presence of $E$. histolytica trophozoites in culture tubes was determined by microscopic examination to determine infectivity.

\section{Quantification of trophozoites from cecal content}

During harvests, cecal content was resuspended into $1 \mathrm{ml}$ of PBS. Then $200 \mu \mathrm{l}$ of cecal content was used to extract DNA using QIAamp Fast DNA
Stool Mini Kit (Qiagen, Hilden, Germany). E. histolytica DNA was quantified using real-time PCR (qPCR) from extracted DNA. For the quantification purpose, DNA was extracted from $10^{5}$ trophozoites to generate six standards by ten times serial dilution. A standard curve was generated from these six standards to quantify trophozoites in samples. The primers and probe used for qPCR are as follows: Eh-probe: Fam/TCATTGAATGAATTGGCCATTT/BHQ; Eh-forward: ATTGTCGTGGCATCCTAACTCA; Ehreverse: GCGGACGGCTCATTATAACA.

\section{H\&E staining, PAS staining, and tuft cell staining}

At harvest, mouse cecal tissue sections were collected and fixed into Bouin's solution for $24 \mathrm{~h}$ and then transferred into $70 \%$ ethanol. Tissue sections were then embedded into paraffin, sectioned and stained by H\&E stain or PAS. Two independent blinded scorers scored the epithelium disruption (ranged from 0 to 3 ) and counted goblet cells $s^{50}$. Goblet cell numbers were normalized to the number of crypts. To determine the number of tuft cells, tissue sections were stained by anti-DCAMKL1 antibody (Cat\# ab 31704, dilution 1:4000)

Preparation of tissue lysate and tissue protein measurement Dissected cecal tissue was mixed with $300 \mu \mathrm{l}$ of lysis buffer 1 (1× HALT protease inhibitor, $5 \mathrm{mM}$ HEPES) followed by bead beating for $1 \mathrm{~min}$. After bead beating, $300 \mu$ of lysis buffer 2 (1× HALT protease inhibitor, $5 \mathrm{mM}$ HEPES, $2 \%$ Triton X-100) was added with the solution and incubated on ice for $30 \mathrm{~min}$. Solutions were centrifuged for $10 \mathrm{~min}$ at $10,000 \times g$, and supernatants were collected. The ST2 protein concentration was measured using R\&D ELISA kits (Minneapolis, MN). IL-33 and IL-25 concentration were measured by ELISA and Luminex assay (R\&D systems). Protein concentrations were normalized to total tissue protein.

\section{RNA extraction and qPCR}

RNA was extracted from cecal tissue using a RNeasy isolation kit (Qiagen, Hilden, Germany). Genomic DNA was removed using a Turbo DNA-free kit (Invitrogen, Carlsbad, CA). RNA was then transcribed to CDNA using a HighCapacity cDNA Reverse Transcription kit (Applied Biosystems, Foster city, CA). Expression of II-5, II-13, II-4, Muc2, Chil3, and Arg1 genes was quantified by qPCR using Sensifast SYBR \& Fluorescein kit (Bioline, London, UK). Gene expression was normalized to Gapdh expression. All procedures were performed following protocols provided in the kits. Primers used for qPCR are as follows: II-13: F-5'-CAGCATGGTATGGAGTGTGGACCT-3', R-5'-ACAGCT GAGATGCCCAGGGAT-3'; AT-60.0 ${ }^{\circ} \mathrm{C}$. II-5: F-5'-AGCAATGAGACGATGAGGCT T-3', R-5'-CCCCCACGGACAGTTTGATT-3'; AT-62.4 ${ }^{\circ} \mathrm{C}$. IL-4: F-5'-CCATATCCA CGGATGCGACA-3', R-5'-CTGTGGTGTTCTTCGTTGCTG-3'; AT-60.0 ${ }^{\circ} \mathrm{C}$. Chil3: F5'-GAAGGAGCCACTGAGGTCTG-3', R-5'-GAGCCACTGAGCCTTCAAC-3'; AT60.0 ${ }^{\circ} \mathrm{C}$. Arg1: F-5'-CAGAAGAATGGAAGAGTCAG-3', R-5'-CAGATATGCAG GGAGTCACC-3'; AT-60.0 ${ }^{\circ} \mathrm{C}$. Muc2: F-5'-GCTGACGAGTGGTTGGTGAATG-3', R-5'-GATGAGGTGGCAGACAGGAGAC-3'; AT: $60.0^{\circ} \mathrm{C}$ Gapdh: F-5'-AACTTTGG CATTGTGGAAGG-3', R-5'-ACACATTGGGGGTAGGAACA-3'; AT: $62.4^{\circ} \mathrm{C}$.

\section{Preparation of single-cell suspension and flow cytometry}

Cecal tissues were cut longitudinally and washed into buffer 1 (HBSS with $25 \mathrm{mM}$ HEPES and 5\% FBS). Epithelial cells were separated from the lamina propria by incubating tissue in buffer 2 (HBSS with $15 \mathrm{mM}$ HEPES, $5 \mathrm{mM}$ EDTA, $10 \% \mathrm{FBS}$, and $1 \mathrm{mM}$ DTT) for $40 \mathrm{~min}$ at $37^{\circ} \mathrm{C}$ with gentle shaking. Then, the lamina propria was dissected into small pieces with scissors and incubated in digestion buffer (RPMI 1640 containing $0.17 \mathrm{mg} / \mathrm{ml}$ Liberase TL (Roche, Basel, Switzerland) and $30 \mu \mathrm{g} / \mathrm{ml}$ DNase (Sigma-Aldrich, St. Louis, MO)) for $30 \mathrm{~min}$ at $37^{\circ} \mathrm{C}$ with gentle shaking. Single-cell suspensions were made by passing the digested tissue through a $100 \mu \mathrm{m}$ cell-strainer followed by a $40 \mu \mathrm{m}$ cell-strainer. Cells were pelleted by centrifuging at $500 \times g$ for $5 \mathrm{~min}$ and reconstituted in FACS buffer (2\% FBS in PBS). For flow cytometry, $1 \times 10^{6}$ cells/sample were incubated with TruStain fcX (BioLegend, San Diego, CA) for $5 \mathrm{~min}$ at room temperature, followed by incubation with LIVE/DEAD Fixable Aqua (Life Technologies, Carlsbad, CA) for $30 \mathrm{~min}$ at $4{ }^{\circ} \mathrm{C}$. Cells were washed with FACS buffer twice before staining with monoclonal antibodies targeted to cell surface markers, followed by incubation for $45 \mathrm{~min}$ at $4{ }^{\circ} \mathrm{C}$. Immune cells were detected by flow cytometry using an LSR Fortessa cytometer (BD Biosciences, San Jose, CA). For transcription factor staining, cells were fixed and permeabilized using Foxp3/transcription factor staining buffer (eBioscience, San Diego, $\mathrm{CA})$ before staining with antibodies. Data were analyzed via FlowJo software. The following monoclonal antibodies were used for staining: CD206 (141716), F4/80 (123133), CD19 (115533), CD5 (100623), CD3 
(100327), FceRla (134317), CD11c (117327), CD90 (105305), CD11b (101215) Ly6C (128005), CD45 (103115), Ly6G (127617), Tbet (505839), from Biolegend (San Diego, CA); ST2 (12-9333-82), RoryT (17-6981-82) from eBiosciences (San Diego, CA); GATA3 (L50-823), SiglecF (552126), CD127 (566377) from BD Bioscience (San Jose, CA).

\section{ILC2 isolation, expansion, and adoptive transfer}

WT C57BL/6J mice were administered $0.75 \mu \mathrm{g}$ IL-33 for 4 days. Mouse colons, spleens, and mesenteric lymph nodes were collected, and single-cell suspensions were made. ILCs were enriched using mouse Lineage Cell Depletion Kit (Milteny Biotec, Bergisch Gladbach, Germany). Enriched cells were in vitro expanded toward ILC2s for 4 days by treating with IL-2 (10 ng/ $\mathrm{ml})$, IL-7 $(10 \mathrm{ng} / \mathrm{ml})$, and $\mathrm{IL}-33(50 \mathrm{ng} / \mathrm{ml})^{15}$. Lin-CD45+CD $127+\mathrm{CD} 90+$ CD25+ST2+ILC2s were then collected by flow sorting followed by intraperitoneal injection of $5 \times 10^{5}$ cells or vehicle per mouse.

\section{Transcriptome microarray}

Colon biopsies were collected from eight adult patients who came to the International Centre for Diarrhoeal Diseases Research, Bangladesh with $E$. histolytica infection. Control samples were collected from the same individuals after 60 days of primary infections during recovery. Microarray data were stored in NCBI's Gene Expression Omnibus (GEO) (http://www. ncbi.nlm.nih.gov/geo/ $/{ }^{18}$. The volcano plot was generated using the DESeq2 package on $\mathrm{R}^{51}$. Consensus PathDB database was used to perform pathway enrichment analysis ${ }^{52}$. Microarray data on mouse colonic tissue are accessible through GEO accession number GSE43372 ${ }^{53}$.

\section{Eosinophil depletion}

For eosinophil depletion, IL-33-treated mice received $40 \mu \mathrm{g}$ anti-SiglecF (clone 238047) or IgG2a isotype control (clone 54447). Successful depletion of eosinophils was confirmed by flow cytometry.

\section{Statistical analysis}

Fisher's exact test was used to compare the infection rate between groups. Student's $t$ test or the Mann-Whitney $U$ nonparametric test was used to make comparisons between two groups. ANOVA was used to compare multiple groups. All the tests were done using GraphPad Prism software.

\section{REFERENCES}

1. Liu, L. et al. Global, regional, and national causes of child mortality: an updated systematic analysis for 2010 with time trends since 2000. Lancet 379, 2151-2161 (2012).

2. Mondal, D., Petri, W. A., Sack, R. B., Kirkpatrick, B. D. \& Haque, R. Entamoeba histolytica-associated diarrheal illness is negatively associated with the growth of preschool children: evidence from a prospective study. Trans. R. Soc. Trop. Med. Hyg. 100, 1032-1038 (2006).

3. Lozano, R. et al. Global and regional mortality from 235 causes of death for 20 age groups in 1990 and 2010: a systematic analysis for the Global Burden of Disease Study 2010. Lancet 380, 2095-2128 (2012).

4. Irusen, E. M., Jackson, T. F. H. G. \& Simjee, A. E. Asymptomatic intestinal colonization by pathogenic Entamoeba histolytica in amebic liver abscess: prevalence, response to therapy, and pathogenic potential. Clin. Infect. Dis. 14, 889-893 (1992).

5. Uddin, M. J., Leslie, J. L. \& Petri, W. A. Host protective mechanisms to intestinal amebiasis. Trends Parasitol. 37, 165-175 (2021).

6. Ralston, K. S. et al. Trogocytosis by Entamoeba histolytica contributes to cell killing and tissue invasion. Nature 508, 526-530 (2014).

7. Bansal, D. et al. An ex-vivo human intestinal model to study Entamoeba histolytica pathogenesis. PLoS Negl. Trop. Dis. 3, e551 (2009).

8. Watanabe, K. et al. Microbiome-mediated neutrophil recruitment via CXCR2 and protection from amebic colitis. PLOS Pathog. 13, e1006513 (2017).

9. Ghadiriani, E. \& Bout, D. T. In vitro killing of Entamoeba histolytica trophozoites by interferon- $\gamma$-activated mouse macrophages. Immunobiology 176, 341-353 (1988).

10. Petri, W. A. et al. Correlation of interferon- $\gamma$ production by peripheral blood mononuclear cells with childhood malnutrition and susceptibility to amebiasis. Am. J. Trop. Med. Hyg. 76, 340-344 (2007).

11. Mondal, D. et al. Association between TNF-a and Entamoeba histolytica diarrhea. Am. J. Trop. Med. Hyg. 82, 620-625 (2010).

12. Noor, Z. et al. Role of eosinophils and tumor necrosis factor alpha in interleukin25-mediated protection from amebic colitis. MBio 8, e02329-16 (2017).

13. Moltke, J., von, Ji, M., Liang, H.-E. \& Locksley, R. M. Tuft-cell-derived IL-25 regulates an intestinal ILC2-epithelial response circuit. Nature 529, 221-225 (2016).
14. Tu, L. et al. IL-33-induced alternatively activated macrophage attenuates the development of TNBS-induced colitis. Oncotarget 8, 27704-27714 (2017).

15. Frisbee, A. L. et al. IL-33 drives group 2 innate lymphoid cell-mediated protection during Clostridium difficile infection. Nat. Commun. 10, 2712 (2019).

16. Monticelli, L. A. et al. IL-33 promotes an innate immune pathway of intestinal tissue protection dependent on amphiregulin-EGFR interactions. Proc. Natl Acad. Sci. 112, 10762-10767 (2015).

17. Barlow, J. L. et al. IL-33 is more potent than IL-25 in provoking IL-13-producing nuocytes (type 2 innate lymphoid cells) and airway contraction. J. Allergy Clin. Immunol. 132, 933-941 (2013).

18. Peterson, K. M. et al. The expression of REG $1 \mathrm{~A}$ and REG $1 \mathrm{~B}$ is increased during acute amebic colitis. Parasitol. Int. 60, 296-300 (2011).

19. Houpt, E. R. et al. The mouse model of amebic colitis reveals mouse strain susceptibility to infection and exacerbation of disease by CD4 + T cells. J. Immunol. 169, 4496-4503 (2002).

20. Schmitz, J. et al. IL-33, an interleukin-1-like cytokine that signals via the IL-1 receptor-related protein ST2 and induces T helper type 2-associated cytokines. Immunity 23, 479-490 (2005).

21. Hayakawa, H., Hayakawa, M., Kume, A. \& Tominaga, S. Soluble ST2 blocks interleukin-33 signaling in allergic airway inflammation. J. Biol. Chem. 282, 26369-26380 (2007).

22. Humphreys, N. E., Xu, D., Hepworth, M. R., Liew, F. Y. \& Grencis, R. K. IL-33, a potent inducer of adaptive immunity to intestinal nematodes. J. Immunol. 180, 2443-2449 (2008)

23. Waddell, A., Vallance, J. E., Hummel, A., Alenghat, T. \& Rosen, M. J. IL-33 induces murine intestinal goblet cell differentiation indirectly via innate lymphoid cell IL13 secretion. J. Immunol. 202, 598-607 (2019).

24. Lidell, M. E., Moncada, D. M., Chadee, K. \& Hansson, G. C. Entamoeba histolytica cysteine proteases cleave the MUC2 mucin in its C-terminal domain and dissolve the protective colonic mucus gel. Proc. Natl Acad. Sci. 103, 9298-9303 (2006).

25. Chadee, K., Petri, W. A., Innes, D. J. \& Ravdin, J. I. Rat and human colonic mucins bind to and inhibit adherence lectin of Entamoeba histolytica. J. Clin. Invest. 80, 1245-1254 (1987).

26. Yamaguchi, Y. et al. Purified interleukin 5 supports the terminal differentiation and proliferation of murine eosinophilic precursors. J. Exp. Med. 167, 43-56 (1988).

27. Sutherland, T. E. et al. Ym1 induces RELMa and rescues IL-4Ra deficiency in lung repair during nematode infection. PLoS Pathog. 14, e1007423 (2018).

28. Schiering, $C$. et al. The alarmin IL-33 promotes regulatory T-cell function in the intestine. Nature 513, 564-568 (2014).

29. Malik, A. et al. IL-33 regulates the IgA-microbiota axis to restrain IL-1a-dependent colitis and tumorigenesis. J. Clin. Invest. 126, 4469-4481 (2016).

30. Kobori, A. et al. Interleukin-33 expression is specifically enhanced in inflamed mucosa of ulcerative colitis. J. Gastroenterol. 45, 999-1007 (2010).

31. Liew, F. Y., Girard, J.-P. \& Turnquist, H. R. Interleukin-33 in health and disease. Nat. Rev. Immunol. 16, 676-689 (2016).

32. Huang, J. et al. Hyperactivity of innate immunity triggers pain via TLR2-IL-33mediated neuroimmune crosstalk. Cell Rep. 33, 108233 (2020).

33. Wong-Baeza, I. et al. The role of lipopeptidophosphoglycan in the immune response to Entamoeba histolytica. J. Biomed. Biotechnol. 2010, 1-12 (2010).

34. Gilmartin, A. A., Ralston, K. S. \& Petri, W. A. Inhibition of amebic cysteine proteases blocks amebic trogocytosis but not phagocytosis. J. Infect. Dis. 221, 1734-1739 (2020).

35. Pichery, M. et al. Endogenous IL-33 is highly expressed in mouse epithelial barrier tissues, lymphoid organs, brain, embryos, and inflamed tissues: in situ analysis using a novel II-33-LacZ gene trap reporter strain. J. Immunol. 188, 3488-3495 (2012).

36. Moussion, C., Ortega, N. \& Girard, J.-P. The IL-1-like cytokine IL-33 is constitutively expressed in the nucleus of endothelial cells and epithelial cells in vivo: a novel 'alarmin'? PLoS One 3, e3331 (2008).

37. Stojkovic, S. et al. Tissue factor is induced by interleukin-33 in human endothelial cells: a new link between coagulation and inflammation. Sci. Rep. 6, 25171 (2016).

38. Ishihara, K. \& Hirano, T. IL- 6 in autoimmune disease and chronic inflammatory proliferative disease. Cytokine Growth Factor Rev. 13, 357-368 (2002).

39. Klion, A. D. \& Nutman, T. B. The role of eosinophils in host defense against helminth parasites. J. Allergy Clin. Immunol. 113, 30-37 (2004).

40. Gil-Recasens, M. E. et al. Increased leucocyte histamine release by Entamoeba histolytica antigen in patients with amoebic abscess of the liver. Parasite Immunol. 6, 211-222 (1984).

41. Lee, Y. A. et al. Entamoeba histolytica-secreted cysteine proteases induce IL-8 production in human mast cells via a PAR2-independent mechanism. Parasite 21, 1 (2014).

42. Eberl, G., Colonna, M., Santo, J. P., Di \& McKenzie, A. N. J. Innate lymphoid cells: a new paradigm in immunology. Science 348, aaa65666 (2015). 
43. Moro, K. et al. Innate production of $\mathrm{TH} 2$ cytokines by adipose tissue-associated cKit+Sca-1 + lymphoid cells. Nature 463, 540-544 (2010).

44. Nakamura, R. et al. Group 2 innate lymphoid cells exacerbate amebic liver abscess in mice. iScience 23, 101544 (2020).

45. Schuijs, M. J. et al. ILC2-driven innate immune checkpoint mechanism antagonizes NK cell antimetastatic function in the lung. Nat. Immunol. 21, 998-1009 (2020).

46. Gieseck, R. L., Wilson, M. S. \& Wynn, T. A. Type 2 immunity in tissue repair and fibrosis. Nat. Rev. Immunol. 18, 62-76 (2018).

47. Mchedlidze, T. et al. Interleukin-33-dependent innate lymphoid cells mediate hepatic fibrosis. Immunity 39, 357-371 (2013).

48. Zeis, P. et al. In situ maturation and tissue adaptation of type 2 innate lymphoid cell progenitors. Immunity 53, 775-792.e9 (2020).

49. Diamond, L. S., Harlow, D. R. \& Cunnick, C. C. A new medium for the axenic cultivation of Entamoeba histolytica and other Entamoeba. Trans. R. Soc. Trop. Med. Hyg. 72, 431-432 (1978).

50. Buonomo, E. L. et al. Microbiota-regulated IL-25 increases eosinophil number to provide protection during Clostridium difficile infection. Cell Rep. 16, 432-443 (2016).

51. Love, M. I., Huber, W. \& Anders, S. Moderated estimation of fold change and dispersion for RNA-seq data with DESeq2. Genome Biol. 15, 550 (2014).

52. Kamburov, A., Stelzl, U., Lehrach, H. \& Herwig, R. The ConsensusPathDB interaction database: 2013 update. Nucleic Acids Res. 41, D793-D800 (2013).

53. Mackey-Lawrence, N. M. et al. Effect of the leptin receptor Q223R polymorphism on the host transcriptome following infection with Entamoeba histolytica. Infect. Immun. 81, 1460-1470 (2013).

\section{ACKNOWLEDGEMENTS}

The authors would like to thank the University of Virginia Flow cytometry, Histology, and Biorepository and Tissue Research Facility cores for technical support. We want to thank Drs Thomas J. Braciale, Janet V. Cross, James E. Casanova, and Chance John Luckey for helpful discussions. The authors would also like to thank the Mann, Ramakrishnan, Marie, and Moonah laboratories for helpful discussions. This work was funded by the National Institutes of Health (NIH) grant R37Al026649 to W. A. P and the Bill \& Melinda Gates Foundation (OPP 1136751). M. J. U. was also supported by the UVA Robert Wagner Fellowship. J. L. L. was also supported by the NIH grant F32DK124048.

\section{AUTHOR CONTRIBUTIONS}

M. J. U. and W. A. P. designed experiments. M. J. U., J. L. L., S. L. B., N. O., B. T., J. R. and M. A. performed all the experiments. J. L. L. and S. L. B. gave important advice about designing the experiments. M. J. U. wrote the original draft and W. A. P., J. L. L. and B. T. reviewed and edited the manuscript. P. K. contributed to analyzing transcriptomic data. S. L. B., A. L. F. and A. N. D. helped to design flow cytometry panels, and A. L. F provided invaluable advice in processing colonic tissue to isolate single-cell suspensions. All the authors reviewed the manuscript.

\section{COMPETING INTERESTS}

The authors declare no competing interests.

\section{ADDITIONAL INFORMATION}

Supplementary information The online version contains supplementary material available at https://doi.org/10.1038/s41385-021-00442-2.

Correspondence and requests for materials should be addressed to W.A.P.J.

Reprints and permission information is available at http://www.nature.com/ reprints

Publisher's note Springer Nature remains neutral with regard to jurisdictional claims in published maps and institutional affiliations.

Access This article is licensed under a Creative Commons Attribution 4.0 International License, which permits use, sharing, adaptation, distribution and reproduction in any medium or format, as long as you give appropriate credit to the original author(s) and the source, provide a link to the Creative Commons license, and indicate if changes were made. The images or other third party material in this article are included in the article's Creative Commons license, unless indicated otherwise in a credit line to the material. If material is not included in the article's Creative Commons license and your intended use is not permitted by statutory regulation or exceeds the permitted use, you will need to obtain permission directly from the copyright holder. To view a copy of this license, visit http://creativecommons. org/licenses/by/4.0/.

(c) The Author(s) 2021 